\title{
SINTERED FeCURe ALLOYS PRODUCED FROM COMMERCIALLY AVAILABLE POWDERS
}

\begin{abstract}
This paper discusses the mechanical properties of materials fabricated from commercially available powders designed for use as a metal matrix of diamond-impregnated composites. The powders with the catalogue numbers CSA and CSA800 produced in China were tested under laboratory conditions. The specimens were fabricated in a graphite mould using hot pressing. The materials were analysed for density, porosity, hardness and static tensile strength. A scanning electron microscope (SEM) was employed to observe the microstructure and fracture surfaces of the specimens. The experimental data was used to determine how the chemical composition of the powders and the process parameters affected the microstructure and properties of the materials. The properties of the sintered materials produced from the Chinese powders were compared with the properties reported for specimens fabricated from cobalt powder (Co SMS). Even though the hot pressed CSA and CSA800 powders had inferior mechanical properties to their cobalt analogue, they seem well-suited for general-purpose diamond-impregnated tools with less demanding applications.

Keywords: sintered alloy, matrix powder, hot pressing, diamond impregnated tools
\end{abstract}

\section{Introduction}

Traditionally, diamond segments of circular saws for cutting natural stones (Fig. 1) have been produced from cobalt powders. From an industrial point of view, the use of cobalt as the metalbond material has a number of advantages [1-5]. Cobalt is available in the form of powders differing in chemical purity as well as the size and shape of particles. Cobalt powders can be compacted to near-full density at a temperature not higher than $850^{\circ} \mathrm{C}$.

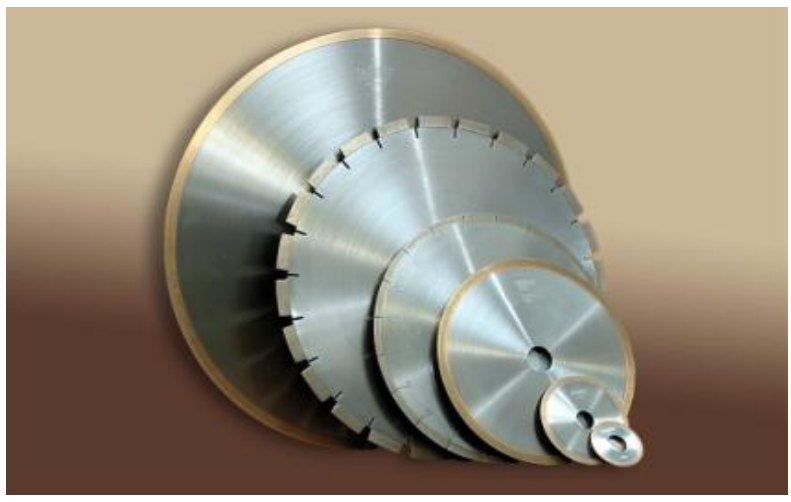

Fig. 1. Diamond-impregnated circular saws by Diament

During the consolidation process, however, some graphitisation of diamond crystals occurs, which may contribute to the worsening of the mechanical properties of the composite. Diamond-cobalt composites are characterised by high tensile strength and high yield strength. A cobalt matrix has very good retention properties. If copper, tin, bronze or tungsten carbide is added to a cobalt powder, it is possible to improve the resistance of the matrix to abrasive wear [6-10].

Recently, however, there has been a significant increase in the price of cobalt. The relationship between the cost of cobalt and that of diamond has also changed. The much lower price of industrial diamond, being a result of higher production levels of this material in China, means that the share of the cost of the matrix material in the total cost of the production of tools has grown substantially. The general trend to reduce the production costs attributable to the changes in the cost of raw materials have forced manufacturers of tools and manufacturers of metal powders to look for new, cheaper matrix materials to replace cobalt. The results of the research on the subject, initiated in the mid-1990s, show that a good solution is to use cheap iron powders instead of cobalt powders [11]. Fine-grained carbonyl iron powders are best suited to produce premixes [12]. Technologically advanced producers of metal powders offer ready-to-use mixtures of metal powders to make diamond-impregnated tools [13]. The major advantage of such powders is their relatively low price and ease of consolidation by hot pressing. The powders are studied both theoretically and experimentally. Positive results suggest that, as a more economical alternative, the Chinese powders will soon supersede conventional cobalt powders in the production of circular saws for cutting natural stone [14].

This paper discusses the properties of sintered materials fabricated under laboratory conditions from two Chinese

\footnotetext{
* KIELCE UNIVERSITY OF TECHNOLOGY, FACULTY OF MECHATRONICS AND MECHANICAL ENGINEERING, PP7. TYSIĄCLECIA AV., 25-314 KIELCE, POLAND

Corresponding author: jamrozek@tu.kielce.pl
} 
powders. In the user's manual [14], the producer specifies that the powders are universal and can be used alone or mixed with other powders to produce diamond-impregnated tools for cutting stones and ceramics.

The study involved determining the influence of the chemical composition of the powders and the parameters of the fabrication process on the microstructure and mechanical properties of the sintered materials produced from two Chinese powders (CSA and CSA800) [14]. The results were compared with the data obtained for the sintered specimens fabricated by hot pressing from cobalt SMS powder [15].

\section{Materials and methods}

The materials under study were fabricated by hot pressing from the following powders:

a) iron-based powder produced by Henan Cut Stone Science \& Technology with a seat in Zhengzhou, China; catalogue number: CSA [11],

b) iron-based powder produced by Henan Cut Stone Science \& Technology with a seat in Zhengzhou, China; catalogue number: CSA 800 [11],

c) cobalt SMS powder ( $\geq 99.7 \%$ Co by weight) with a particle size of about $1.0 \mathrm{~mm}$ (Fisher number) produced by Belgium-based UMICORE.

The size and distribution of particles in the three powders are shown in Fig. 2.

Before the powders were consolidated, they were analysed using a JSM-7100F scanning electron microscope (SEM) equipped with an OINA-AZtec microanalysis system.

The SEM images (for example, Fig. 2a) and the spectra collected from the surface of the CSA powder particles show that it is not possible to differentiate between the elements constituting the powder. This suggests that it is an alloy powder.

The next step of the study was to consolidate the powders by hot pressing in a graphite mould, as suggested by the producer. The mould can produce 10 specimens with nominal dimensions $\sim 7 \times 6 \times 40 \mathrm{~mm}$ simultaneously. The hot pressing process was performed at a temperature of $850^{\circ} \mathrm{C}$ and a pressure of $35 \mathrm{MPa}$. Higher pressure could not be applied because of the limited strength of the graphite mould. Hot pressing was conducted in an atmosphere of nitrogen using an ARGA CAR1001 hot press furnace. The sintering time was 3 minutes.

The sintered materials were tested for density and hardness according to Norm PN-EN ISO 2738:2001. Density was measured by weighing the specimens both in air and in water using a WPA120 hydrostatic weighing system. The density measurement results were used to determine the porosity of the sintered materials. The hardness of the sintered materials was measured at a load of $10 \mathrm{kG}$ using the Vickers method. The process parameters of hot pressing and the measurement results concerning density and hardness are given in Table 1.

The tensile tests were conducted using an INSTRON 4502 universal testing machine. The experimental data was used to calculate: the offset yield strength $R_{0.2}$, the tensile strength $R_{m}$, and the maximum relative elongation $(\varepsilon)$. The results of the static tensile tests and the stress-strain curves plotted for the sintered materials produced from the CSA, CSA800 and Co(SMS) powders are provided in Table 2 and Figs. 3a-c. a)

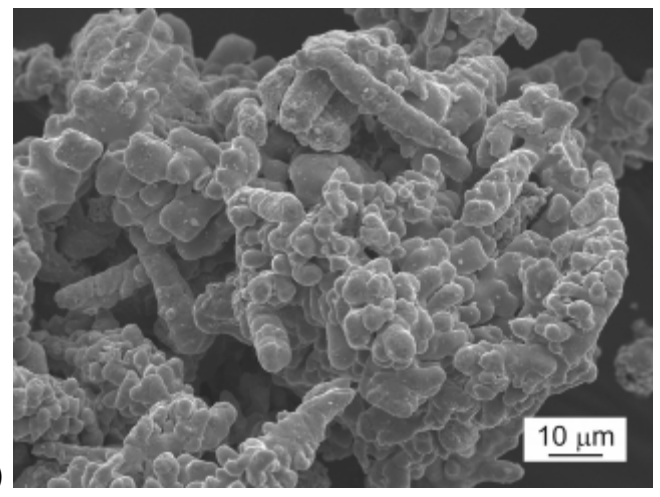

b)

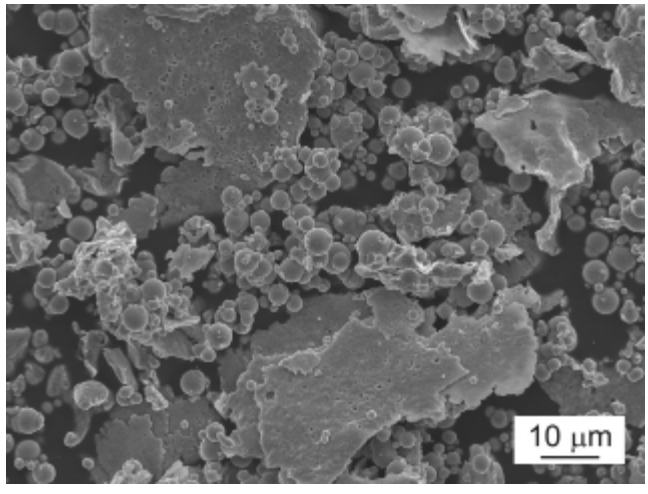

c)

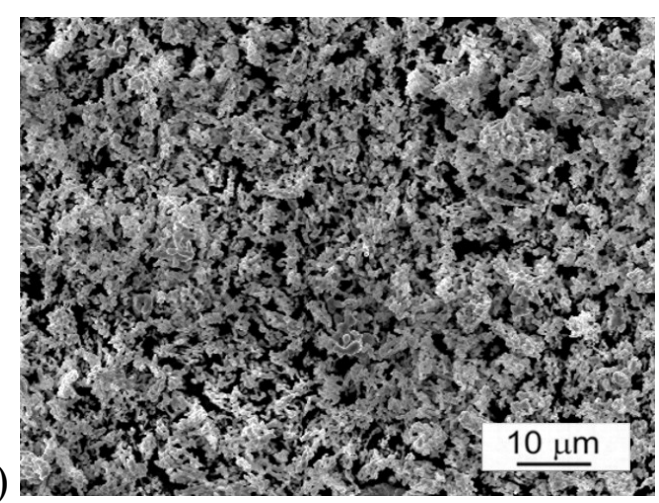

Fig. 2. Images of the powders used in the experiments a) CSA b) CSA800 c) Co(SMS) 
Hot pressing parameters and the measurement results (density, porosity and hardness)

\begin{tabular}{|c|c|c|c|c|c|}
\hline \hline Powder & $\begin{array}{c}\text { Hot pressing } \\
\text { conditions }\end{array}$ & $\begin{array}{c}\text { Density } \\
{\left[\mathbf{g} / \mathbf{c m}^{3}\right]^{*}}\end{array}$ & $\begin{array}{c}\text { Theore- } \\
\text { tical } \\
\text { density } \\
{\left[\mathbf{g} / \mathbf{c m}^{3}\right]}\end{array}$ & $\begin{array}{c}\text { Poro- } \\
\text { sity } \\
{[\%]}\end{array}$ & HV10* \\
\hline $\mathrm{CSA}$ & $\begin{array}{c}850^{\circ} \mathrm{C} / 35 \mathrm{MPA} \\
/ 3 \mathrm{~min}\end{array}$ & $\begin{array}{c}8.06 \\
\pm 0.02\end{array}$ & 8.36 & 3.60 & $\begin{array}{c}145.5 \\
\pm 9.9\end{array}$ \\
\hline $\mathrm{CSA} 800$ & $\begin{array}{c}850^{\circ} \mathrm{C} / 35 \mathrm{MPA} \\
/ 3 \mathrm{~min}\end{array}$ & $\begin{array}{c}8.13 \\
\pm 0.01\end{array}$ & 8.33 & 2.51 & $\begin{array}{c}223.1 \\
\pm 10.2\end{array}$ \\
\hline $\mathrm{Co}$ (SMS) & $\begin{array}{c}850^{\circ} \mathrm{C} / 35 \mathrm{MPa} \\
/ 3 \mathrm{~min}\end{array}$ & $\begin{array}{c}8.74 \\
\pm 0.04\end{array}$ & 8.90 & 1.80 & $\begin{array}{c}271.0 \\
\pm 3.0\end{array}$ \\
\hline
\end{tabular}

* Confidence ranges were established for a confidence level of 0.95
Results of static tensile tests

\begin{tabular}{|c|c|c|c|c|c|}
\hline Material & $\begin{array}{c}\text { Modulus } \\
\text { of elasticity } \\
\boldsymbol{E}^{*} \\
{[\mathbf{G P a}]}\end{array}$ & $\begin{array}{c}\text { Poisson's } \\
\text { ratio* }\end{array}$ & $\begin{array}{c}\text { Offset yield } \\
\text { strength } \\
\boldsymbol{R}_{\mathbf{0 . 2}} \\
{[\mathbf{M P a}]}\end{array}$ & $\begin{array}{c}\text { Tensile } \\
\text { strength } \\
\boldsymbol{R}_{\boldsymbol{m}} \\
{[\mathbf{M P a}]}\end{array}$ & $\begin{array}{c}\text { Maximum } \\
\text { elongation } \\
\boldsymbol{\varepsilon} \\
{[\%]}\end{array}$ \\
\hline CSA & 156 & 0.32 & $251.7 \pm 7.6$ & $\begin{array}{c}382.8 \\
\pm 13.9\end{array}$ & $8.2 \pm 2.2$ \\
\hline CSA800 & 158 & 0.32 & $401.7 \pm 42.5$ & $\begin{array}{c}594.0 \\
\pm 11.9\end{array}$ & $3.6 \pm 0.22$ \\
\hline Co(SMS) & 205 & 0.30 & $404.5 \pm 25.4$ & $\begin{array}{c}865.0 \\
\pm 12.0\end{array}$ & $19.5 \pm 1.5$ \\
\hline
\end{tabular}

* determined with the acoustic method

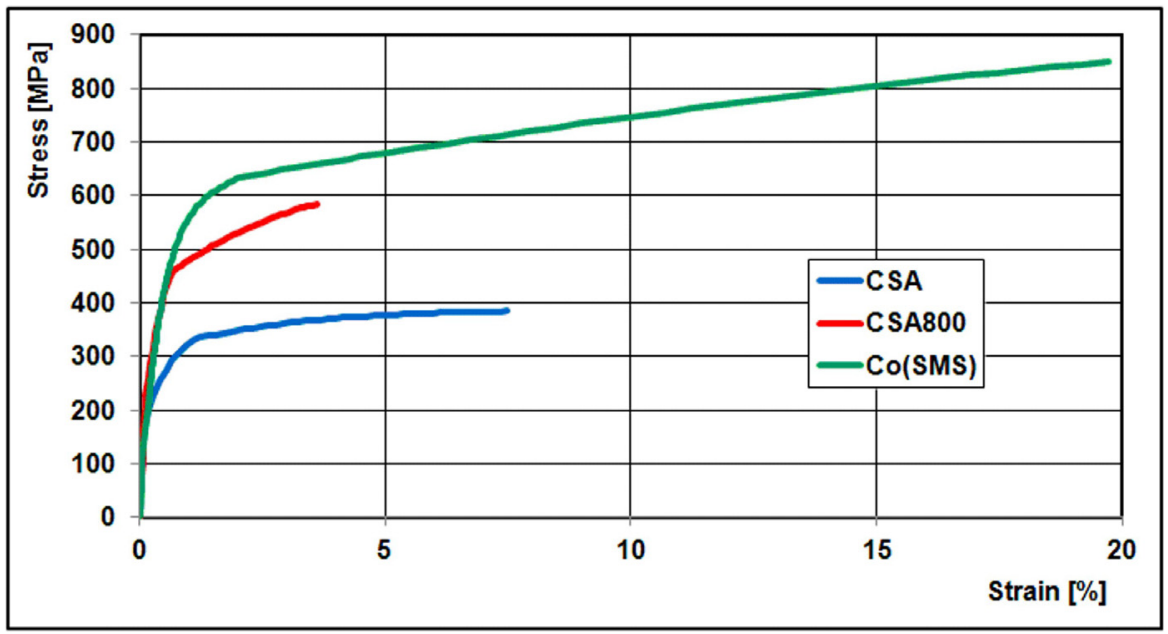

Fig. 3. Stress-strain curves for the sintered CSA, CSA800 and Co(SMS) powders

a)

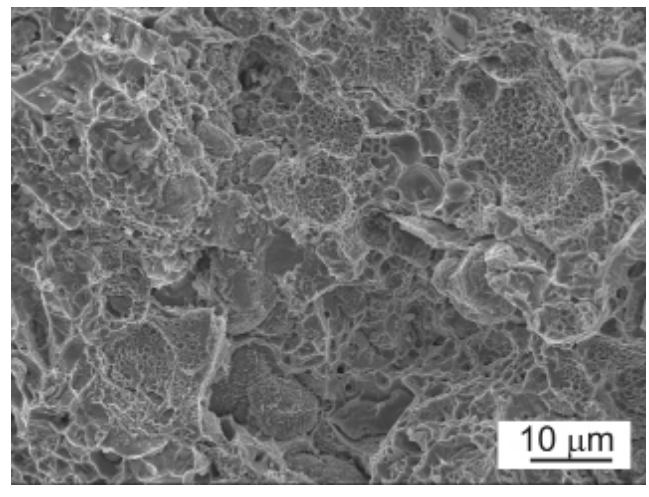

b)

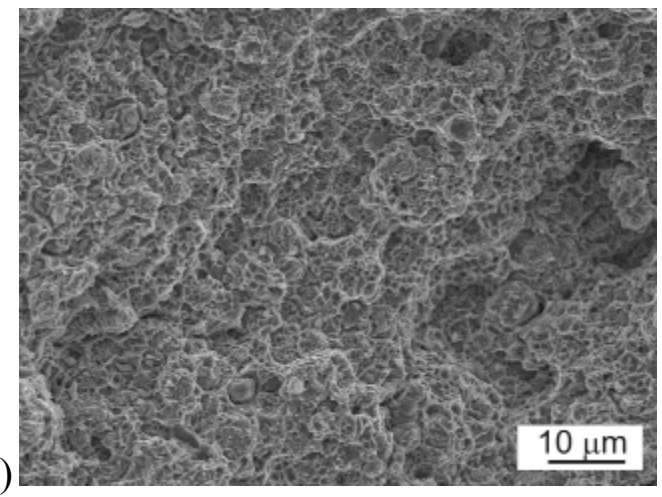

c)

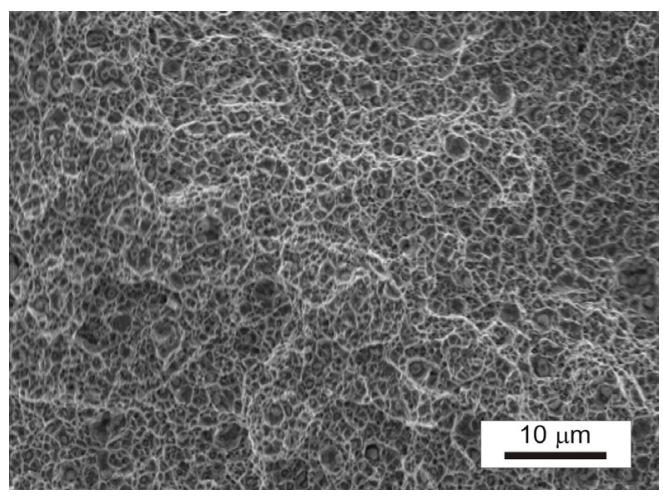

Fig. 4. Fracture surfaces after tensile tests: a) CSA, b) CSA800 c) Co(SMS) 


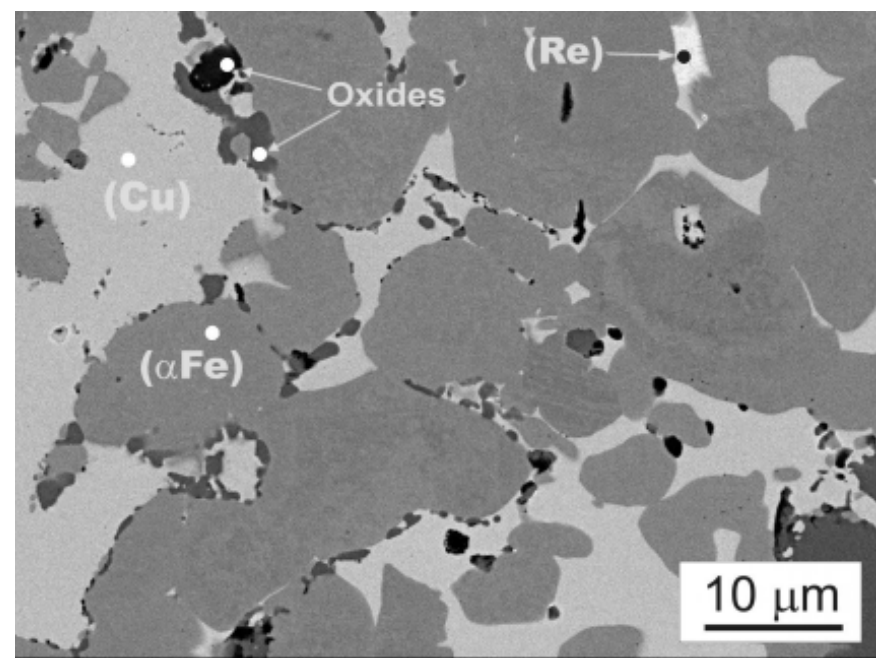

Fig. 5. Microstructure of the sintered CSA powder

TABLE 3

Composition of the phases in the CSA powder

\begin{tabular}{|c|c|c|c|c|c|c|c|c|c|c|}
\hline \hline Element & $\mathbf{O}$ & $\mathbf{F e}$ & $\mathbf{C u}$ & $\mathbf{Z n}$ & Sn & Sm & Y & La & Ce & Totals \\
\hline $\begin{array}{c}\text { Spectrum 1. } \alpha \text { Fe solution } \\
\text { Weight \% }\end{array}$ & - & 95.92 & 3.36 & 0.13 & 0.25 & 0.07 & 0.27 & - & - & $100 \%$ \\
\hline $\begin{array}{c}\text { Spectrum 2. Cu solution } \\
\text { Weight \% }\end{array}$ & - & 3.66 & 82.86 & 7.23 & 5.84 & 0.23 & 0.18 & - & - & $100 \%$ \\
\hline $\begin{array}{c}\text { Spectrum 3. Metal oxides } \\
\text { Weight \% }\end{array}$ & 69.73 & 14.05 & 9.97 & 2.65 & 1.34 & 0.22 & 0.65 & 0.48 & 0.91 & $100 \%$ \\
\hline $\begin{array}{c}\text { Spectrum 4. Re solution } \\
\text { Weight \% }\end{array}$ & - & 2.19 & 27.60 & - & 40.76 & 2.60 & 0.26 & 5.92 & 20.67 & $100 \%$ \\
\hline
\end{tabular}

TABLE 4

Composition of the phases in the CSA800 matrix

\begin{tabular}{|c|c|c|c|c|c|c|c|c|c|c|c|}
\hline \hline Element & $\mathbf{O}$ & $\mathbf{F e}$ & $\mathbf{C u}$ & $\mathbf{Z n}$ & $\mathbf{S n}$ & $\mathbf{S m}$ & $\mathbf{P b}$ & $\mathbf{Y}$ & $\mathbf{L a}$ & $\mathbf{C e}$ & Totals \\
\hline $\begin{array}{c}\text { Spectrum 1. }(\alpha) \text { Fe solution } \\
\text { Weight \% }\end{array}$ & 0.68 & 94.76 & 3.09 & - & - & 1.21 & - & 0.27 & - & - & $100 \%$ \\
\hline $\begin{array}{c}\text { Spectrum 2.Cu solution } \\
\text { Weight \% }\end{array}$ & - & 4.17 & 82.09 & 7.20 & 6.09 & 0.18 & 0.28 & - & - & - & $100 \%$ \\
\hline $\begin{array}{c}\text { Spectrum 3. Metal oxides } \\
\text { Weight \% }\end{array}$ & 16.66 & 42.23 & 22.84 & 16.57 & 0.97 & 0.22 & 0.15 & - & 0.14 & 0.21 & $100 \%$ \\
\hline
\end{tabular}

The tensile specimens were then examined using a JSM7100F scanning electron microscope equipped with an OINAAZtec EDS system. The fracture surfaces of the materials studied are presented in Fig. 4. Their microstructures and the EDS data for the phases in the sintered powders are shown in Figures 5-10.

Table 3 shows the composition (weight $\%$ ) of the phases in the sintered CSA powder. The EDS spectra were collected at points 1, 2, 3 and 4 marked in Figure 5.

Table 4 shows the composition (weight \%) of the sintered CSA powder obtained using EDS. The spectra were collected at points 1, 2 and 3 marked in Figure 7.

Collected from the surface of the powder particles spectrum confirmed that the test the powder is a pure cobalt powder.

\section{Results and discussion}

From the EDS analysis of the CSA powder it is evident that no constituent elements can be differentiated, which suggests that it is an alloy powder. The spectra collected from the surface indicate that the powder contains $45 \%$ of $\mathrm{Fe}, 50 \%$ of $\mathrm{Cu}, 3 \%$ of $\mathrm{Zn}$ and $2 \%$ of $\mathrm{Sn}$.

The spectra collected from the surface of the CSA800 powder show that the powder contains crude of carbonyl iron mixed with irregular, much coarser particles of pre-alloyed bronze (B663). The EDS analysis reveals that the bronze powder is composed of up to $6 \%$ of zinc, up to $3 \%$ of tin and up to $1 \%$ of lead.

As shown in Table 1, the CSA and CSA800 alloys have an interesting combination of mechanical properties. The important characteristics of the CSA alloy include high hardness 


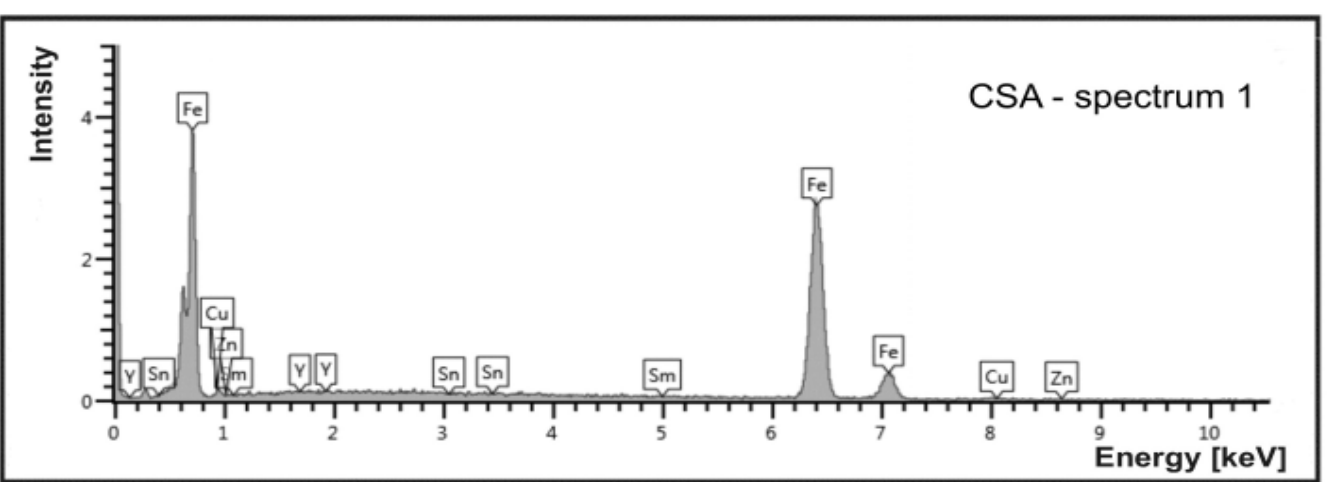

a) $\alpha$ Fe solution

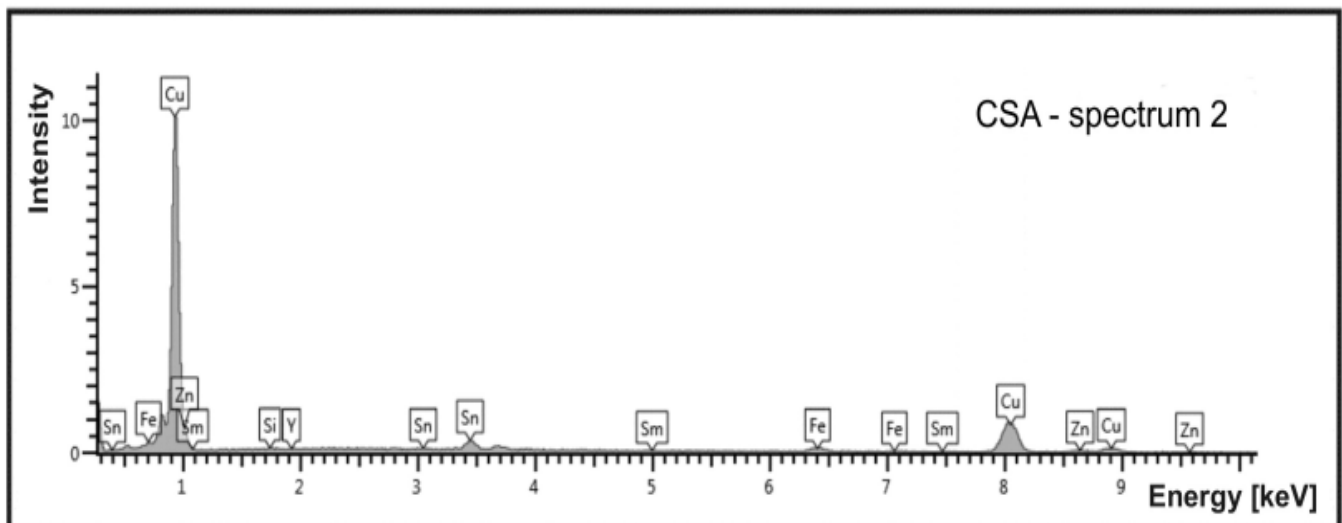

b) $\mathrm{Cu}$ solution

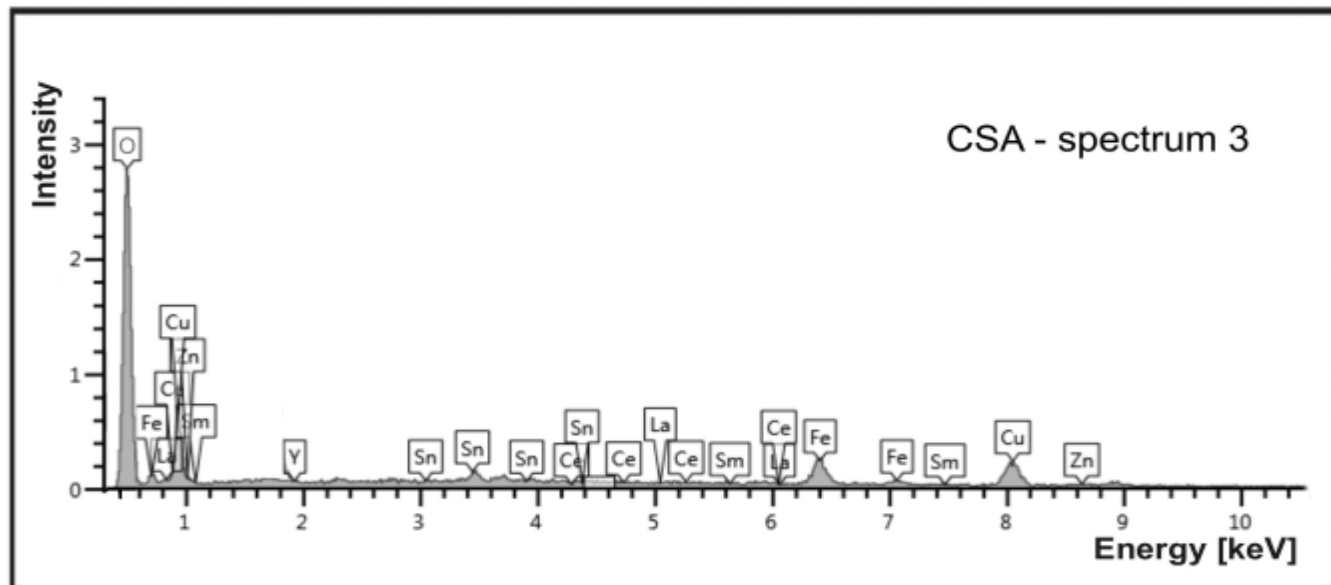

c) metal oxides

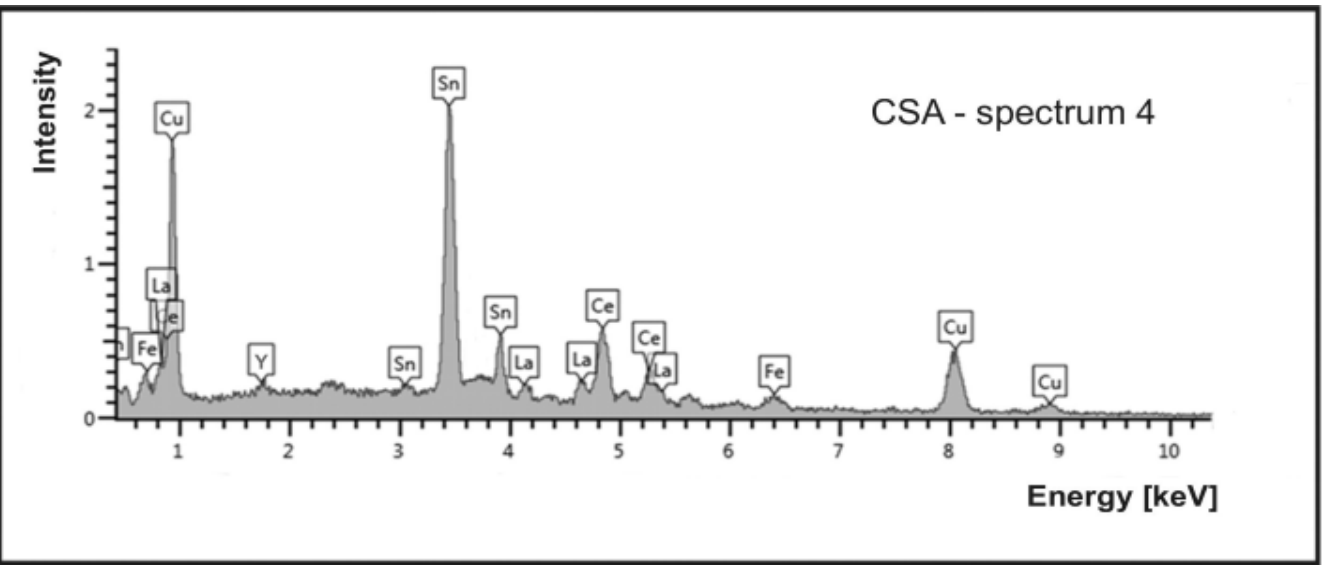

d) Re solution

Fig. 6. Sum spectra of the phases in the sintered CSA powder corresponding to the points in the microstructural image in Figure 5 


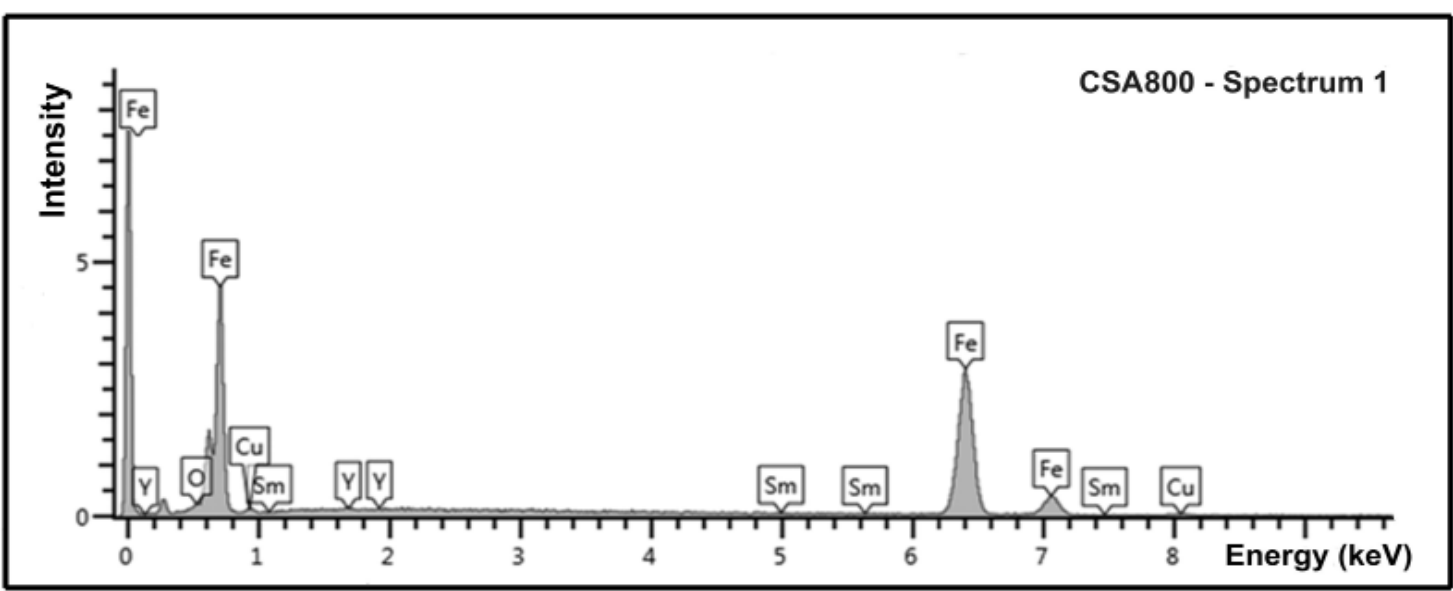

a) $\alpha \mathrm{Fe}$ solution

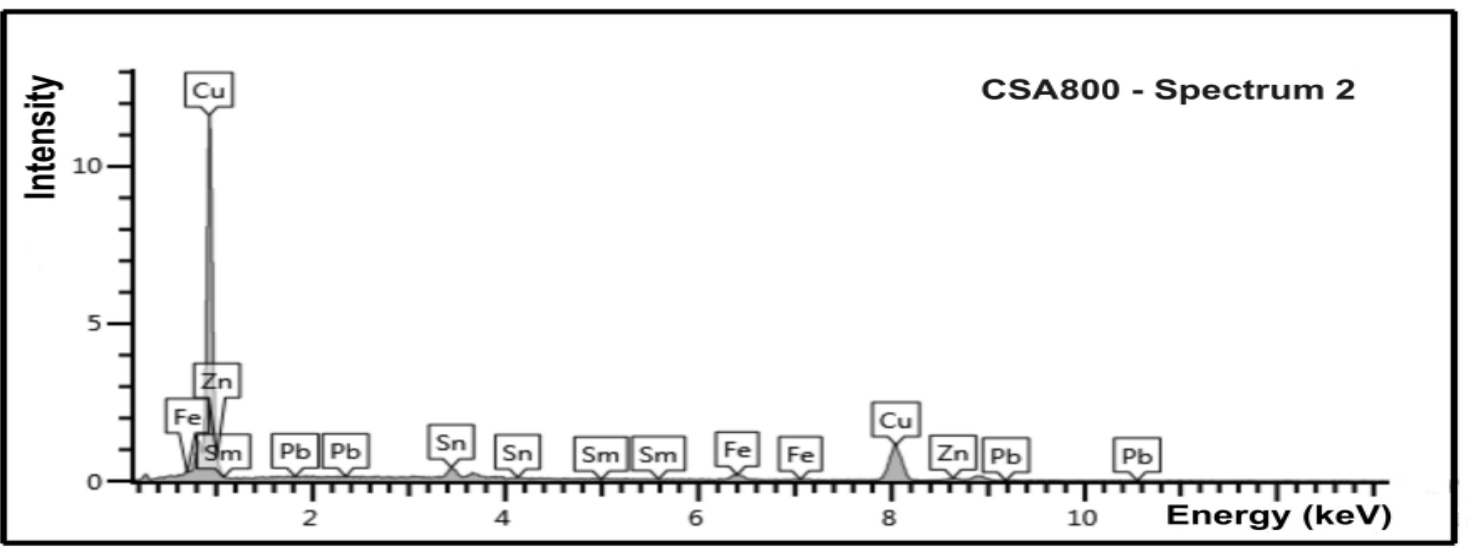

b) $\mathrm{Cu}$ solution

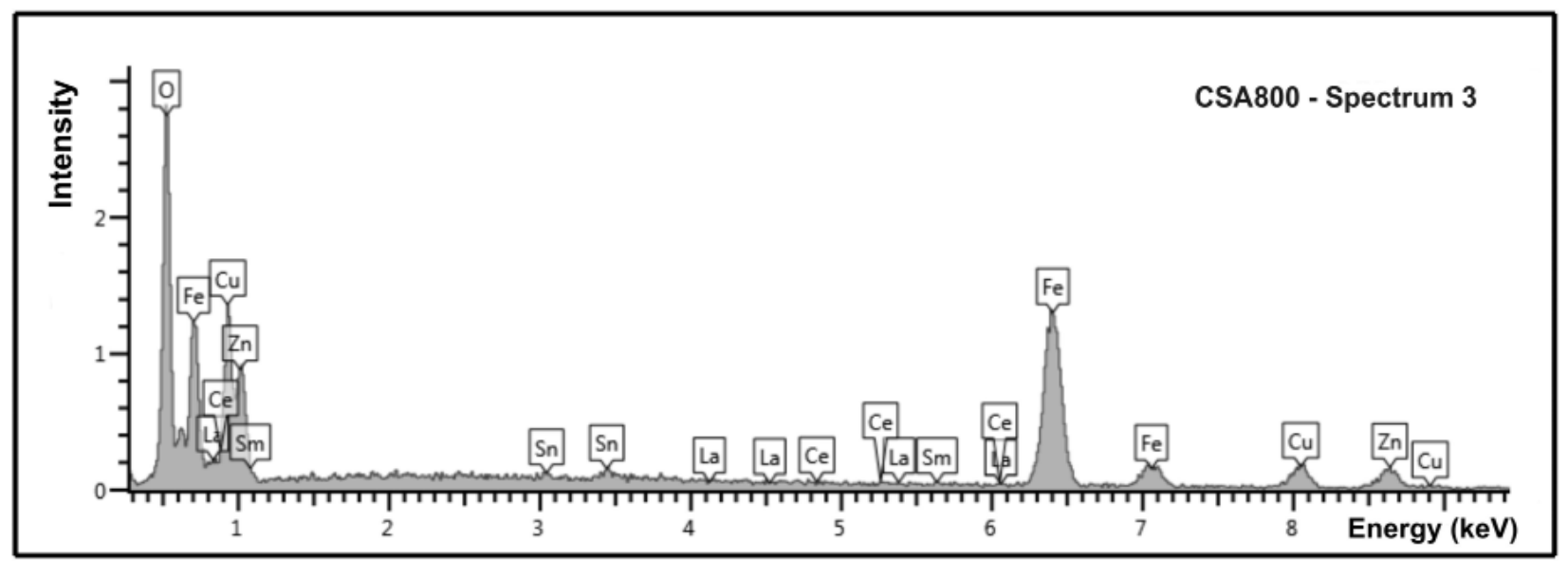

c) metal oxides

Fig. 7. Microstructure of the sintered CSA 800 powder

(145.5 HV10), high tensile strength (382.8 MPa) and high offset yield strength $(251.7 \mathrm{MPa})$; its drawback, however, is high maximum elongation (8.2\%).

The CSA800 alloy exhibits the following properties: high hardness (223 HV10), high tensile strength (591 MPa) and high offset yield strength (404 MPa) with a maximum elongation of $3.3 \%$.

The fractographic examination revealed that in both cases it was a dimpled ductile failure.
The results of the EDS elemental analysis of the metallographic specimens show that the sintered CSA and CSA800 powders have a complex multi-phase microstructure.

The examination of the sintered CSA material confirmed the presence of $\mathrm{Fe}$ (42-52\% by weight), $\mathrm{Cu}$ (48-53\%), Zn (2$3 \%), \mathrm{Sn}(2 \%)$ and traces of rare earth metals such as Sm, Y, La and $\mathrm{Ce}$ (each less than 3\%). As can be seen from the image of the microstructure (Figs. 5,6a-d), the alloy consists of a solid solution of $\mathrm{C}$ in a-Fe, a solid solution of $\mathrm{Sn}$ and $\mathrm{Zn}$ in $\mathrm{Cu}$, dark 


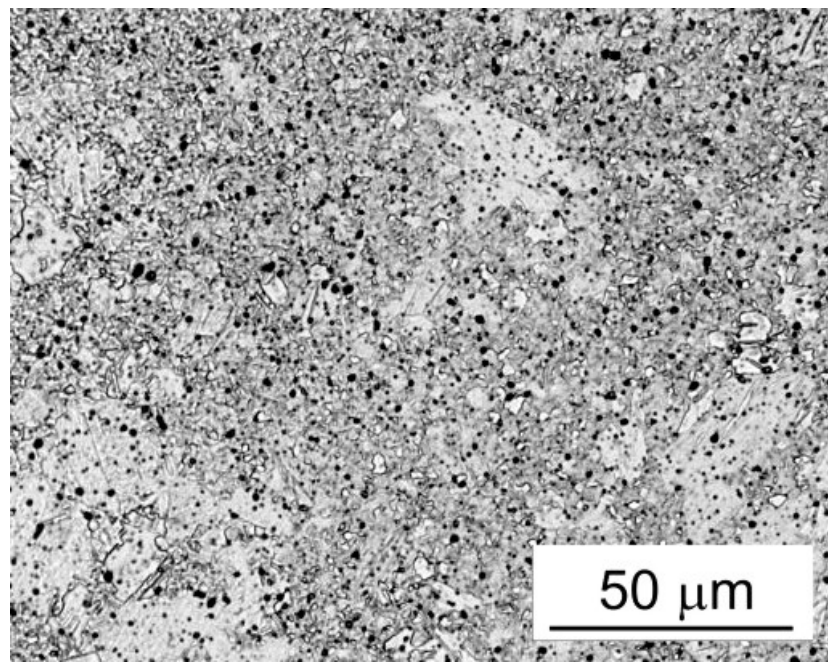

Fig. 8. Sum spectra of the phases in the sintered CSA800 powder for the areas marked in Figure 7

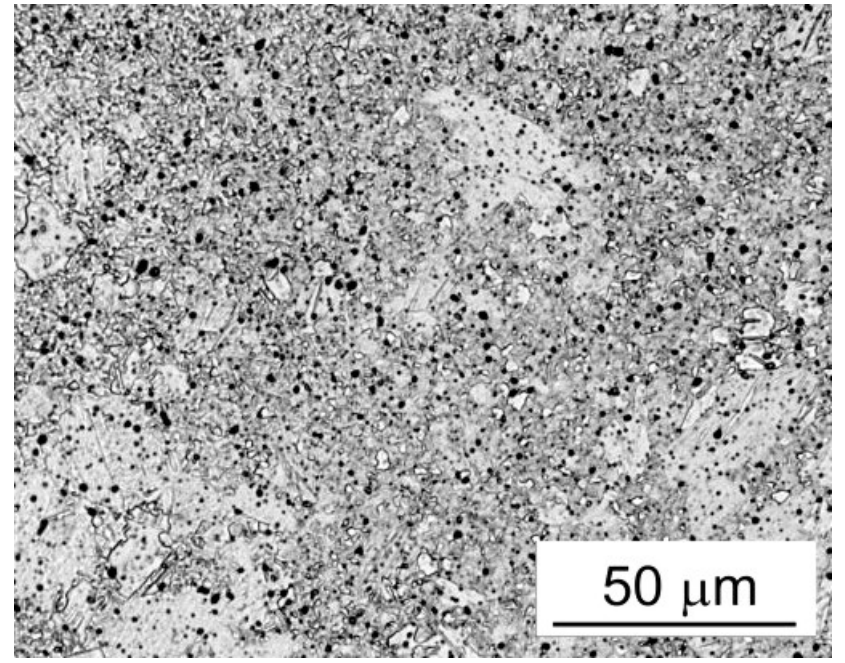

Fig. 9. Microstructure of the sintered Co(SMS) powder

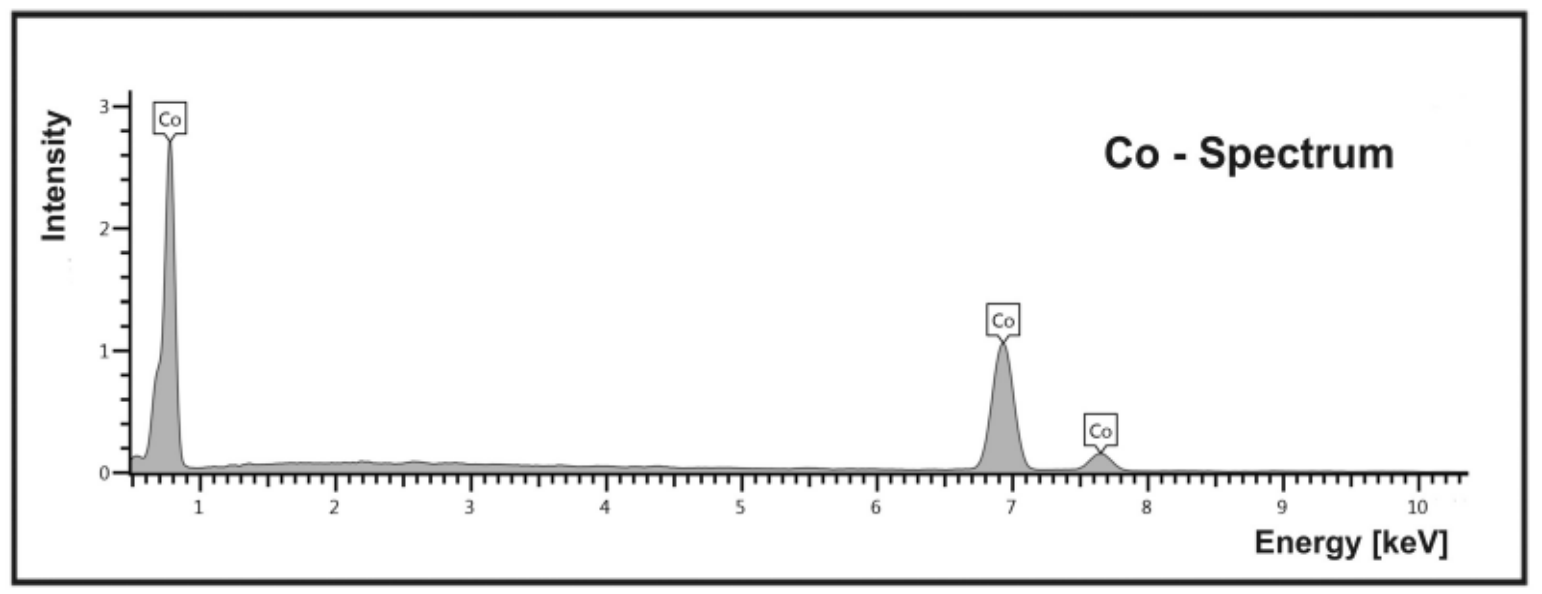

Fig. 10. EDS data for the sintered Co(SMS) powder shown in Figure 9

areas representing metal oxides and sparsely distributed single white areas being a solid solution of rare earth metals in tin and copper with $21 \%$ of $\mathrm{Ce}, 6 \%$ of $\mathrm{La}$ and $3 \%$ of Sm.

The EDS analysis of the sintered CSA 800 powder confirmed the presence of $\mathrm{Fe}$ ( $42-57 \%$ by weight), $\mathrm{Cu}(35-51 \%), \mathrm{Zn}$ $(3-4 \%)$, Sn $(3 \%)$ and $\mathrm{Pb}(<1 \%)$ and traces of rare earth metals. As can be seen from (Figs. 7,8a-c) the alloy consists of a solid solution of carbon in (a-Fe) iron, a solid solution of $\mathrm{Sn}$ and $\mathrm{Zn}$ in $\mathrm{Cu}$ and dark areas being a mixture of metal oxides. Despite the occurrence of $\mathrm{Pb}$ peaks in the EDS spectra, no inclusions of $\mathrm{Pb}$ were observed in the structure.

The conclusions drawn from the study are as follows:

a) the CSA and CSA800 powders are very attractive materials because of their low price and ease of consolidation by hot pressing; their strength and plastic properties can also be easily modified to suit a wide range of applications.

b) the tensile strength and yield strength of the CSA material can be improved by properly modifying the chemical composition of the powder. As provided in the catalogue, the CSA powder is very basic in composition; hence its relatively low strength properties. It can be used alone or with some metallic additives, for example, $\mathrm{Ni}, \mathrm{WC}, \mathrm{W}$ and Co.

c) the properties of the two materials can be modified by changing the temperature of hot pressing.

d) materials produced from the CSA powder contain elements that act as catalysts during the production of synthetic diamonds. If the matrix of a diamond-impregnated tool is made of the CSA powder, there is very good retention of diamond particles within the composite material during the tool operation. Mechanical or/and chemical bonding occurs between the diamond particles and the matrix material. The effectiveness of the mechanical bonding is dependent on the elastic and plastic properties of the matrix material. The relationship between the retention of diamond crystals and the mechanical properties of the matrix material was discussed in earlier works by the author $[9,16]$.

It is important to note that although the strength properties of the alternative materials, i.e. CSA and CSA800, are worse than those of cobalt, their hardness, yield strength and tensile strength are sufficiently high to satisfy the criteria of less demanding applications of general purpose tools. 
1720

\section{REFERENCES}

[1] J. Konstanty, Cobalt as a matrix in diamond impregnated tools for stone sawing applications. PhD thesis, $2^{\text {nd }}$ Edition, AGH University of Science and Technology, Krakow, Poland, 2003.

[2] J. Konstanty, Powder Metallurgy Diamond Tools, 2005 Elsevier, Oxford.

[3] A. Romański, Development of metal matrix for sintered diamonds tools. PhD thesis, AGH University of Science and Technology, Krakow, Poland, 2015, (In Polish).

[4] J. Borowiecka-Jamrozek, Arch. Metall. Mater. 58 (1), 5-8 (2013).

[5] J. Konstanty, Powd. Metall. 56, 184-190 (2013).

[6] S. Rimlinger, The Cobalt Conference, The Royal Garden Hilton, London, England, 144 (1999).

[7] J. Konstanty, A. Bunsch, Powd. Metall. 34 (3), 195-198(1991).

[8] J. Borowiecka-Jamrozek, J. Konstanty, Adv. Mat. Res. 1052, 520-523(2014).
[9] J. Borowiecka-Jamrozek, J. Lachowski, Arch. Metall. Mater. 59 (2), 443-446 (2014).

[10] J. Borowiecka-Jamrozek, Conference on Metallurgy and Materials, METAL2013, Brno, Czech Republic, Thomson Reuters 14321437 (2013)

[11] V.A. Mechnik, Powd. Metall. Met. Ceram. 52 (9-10), 577-587 (2014).

[12] J. Konstanty, D. Tyrała, A. Radziszewska, Arch. Metall. Mater. 54 (4), 1051-1058 (2009).

[13] H. Nanbin, G. Dianyue, Diam. Appl. Techn. 23-30 (2013), www. gmassdiamante.com.

[14] CSA series Basic Alloy powder for Diamond Tools User's Manual, Henan CUT-Stone Science \& Technology, CO., LTD, Zhengzhou.

[15] J. Borowiecka-Jamrozek, Conference on Metallurgy and Materials, METAL2015, Brno, Czech Republic, (2015), Thomson Reuters (in press).

[16] J. Borowiecka-Jamrozek, J. Lachowski, Adv. Mat. Res. 874, 127132 (2014). 